\title{
Harmonic compensation using a single phase active filter
}

\author{
J. R. Mattar, J. C. Strutz, S. V. G. Oliveira, R. Hausmann and A. Péres \\ Department of Electrical and Telecommunications Engineering \\ University of Blumenau \\ Rua São Paulo, 3250 - 89030-000, Blumenau, SC - Brazil \\ Phone:+55 47 32216022, e-mail: aperes.furb@gmail.com
}

\begin{abstract}
This work presents the implementation of a singlephase parallel active filter for harmonic compensation. The idea is to optimize the processed power by the active single-phase filter restricting the compensation only to harmonic currents without processing the linear reactive one. It is made a comparison study of processed power by a conventional active power filter compensating the entirely reactive power and another compensating only the harmonic contents. It is presented the control methodology employed, the power circuit design and the results obtained through a 500VA experimental prototype.
\end{abstract}

\section{Key words}

Active power filter, full-bridge inverter, harmonic compensation, power quality, single-phase.

\section{Introduction}

The development of new technologies in the area of electronics has provided numerous benefits to humanity. The use of electrical and electronic equipment in residential, commercial and industrial electrical installations has been growing dramatically in recent years. The proliferation of this type of equipment has caused great concern, since they absorb non sinusoidal currents from the mains, causing harmonic distortion. For this reason the problem of power quality from harmonic distortion has been the subject of much interest and discussion in recent years [1]-[8].

Many solutions have been proposed, for example, the use of passive and active filters [2], [3].

The passive tuned filter has some significant disadvantages, such as: tuning frequency variation with temperature and with the aging of the capacitors [2]-[4].

The shunt solution is the most widely used in low- and medium-power applications due to simplicity, effectiveness, and harmonic-rejection capabilities [5]-[8]. Shunt filters are usually applied to three-phase systems where a large capacity is required [5], [6]. However, single-phase active filters can be applied in adjustablespeed motor drives fed by a single-phase utility, in airconditioning systems, or in rural areas supplied by a single-wire with earth-return power system [5].
The majority of active power filters (APF) compensate the displacement factor and the distortion factor of the power factor. In this paper an active power filter is proposed to compensate only the distortion factor, restricting the compensation of harmonic currents without processing the purely inductive reactive one.

The displacement factor could be compensated by the use of capacitors, since this method is extremely widespread and efficient for this type of correction. Using this technique one can reduce the volume, weight and the total cost of the active filter and improve the system efficiency.

\section{Comparison between the two techniques}

The active power filters are usually employed to correct the entirely power factor where are installed many nonlinear loads [6], [7]. It is connected in parallel with the network and the load, which acts as a device that injects or drains the distorted load current correcting the power factor to a unity value [1]-[8].

In Fig. 1 it can be seen that the current in the source is formed by the active filter current added to the load current resulting in an entirely sinusoidal current in the power grid.

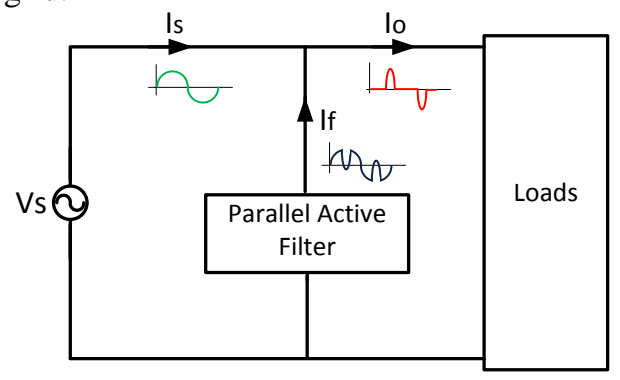

Fig. 1. The main current in a parallel active filter.

As can be seen in (1) the power factor is composed by the product between the distortion factor and the displacement factor. The distortion factor is the relationship between the effective fundamental current and the effective total current or a relation of THD, as shown in (2), and the displacement factor is the lag 
between voltage and current to the fundamental frequency, as shown in (3).

$$
\begin{aligned}
& \mathrm{PF}=\frac{1}{\sqrt{1+\mathrm{THD}_{\mathrm{i}}^{2}}} \cdot \cos \varphi_{1} \\
& \mathrm{~F}_{\text {Distortion }}=\frac{1}{\sqrt{1+\mathrm{THD}_{\mathrm{i}}^{2}}} \\
& \mathrm{~F}_{\text {Displacement }}=\cos \varphi_{1}
\end{aligned}
$$

The conventional active power filter corrects the entirely power factor and, for this reason, its power is dependent on the distortion factor and the displacement factor one. In other words the conventional active filter compensates the displacement and distortion factor [6,7]. On the other hand the proposed strategy used in this work makes the active power filter to correct only the distortion factor and, for this reason, the processed power does not depend on the displacement factor. In other words the proposed strategy used compensates only the harmonic currents without processing any reactive power from the linear loads.

Using (1) it is possible to trace the curves presented in Fig. 2. This figure shows a comparison between the processed reactive power by an active power filter using the conventional strategy and the proposed one as a function of the load current total harmonic distortion (THDi). For comparative purposes it is used in this figure a load displacement factor of 0.7 .

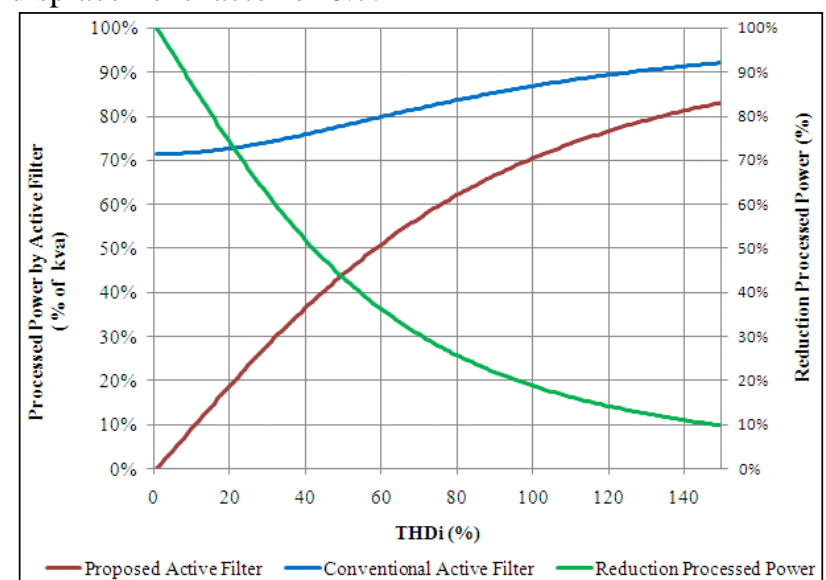

Fig. 2. Comparison between the processed power by the conventional and the proposed strategy applied in an active power filter as a function of the THDi.

It is evidenced through Figure 2 that the power processed by the active power filter driven by conventional strategy is relatively larger than the processed power by the proposed strategy used. Furthermore, it turns out that the lower the total harmonic distortion the greater the derating processed power by the proposed active power filter.

Using the Fig. 2 one can make a comparison between the power processed by the two strategies employed in the APF, whereas in both situations, the current harmonic distortion is $20 \%$. In this case, the reduction of the total processed power by the proposed strategy is $73 \%$. However, the proposed strategy corrects only the reactive power from the harmonic distortion, keeping the load displacement factor unchanged. Therefore, to fix the power factor is necessary the installation of capacitors in parallel with this filter. In this way, depending on the amount of installed capacitors, one can obtain the desired power factor. In conventional filters one cannot control this power factor, since due to its control strategy; the power factor will be always the closest to the unity.

According [2], the estimated cost for the power factor correction through the use of capacitors is US\$ $100.00 / \mathrm{kVAr}$. The estimated cost for the power factor correction using an active power filter is US\$ $1,000.00 / \mathrm{kVAr}$. That is, the active correction cost is 10 times higher than the cost of correction through the use of capacitors.

Figure 3 shows the costs to fix a hypothetical load that consumes $10 \mathrm{kVA}$ and has a power factor equal to 0.7 . These costs are dependent to the THDi. The cost curves of the APF consider the cost of the filter itself plus the cost of capacitors needed to power factor correction. Remember that currently the minimum power factor in Brazil is 0.92 and for this reason the graph of Fig. 3 shows the cost in order to obtain different levels of power factor. If a conventional strategy control is applied to an APF is obtained an unity power factor, but if it is used the proposed strategy the power factor obtained will be equal to 0.92 . Another important detail is that in order to increase the power factor of 0.92 to the unity, approximately $80 \%$ more reactive power will be necessary and it will directly impacts on the final costs of the solution for the power factor correction.

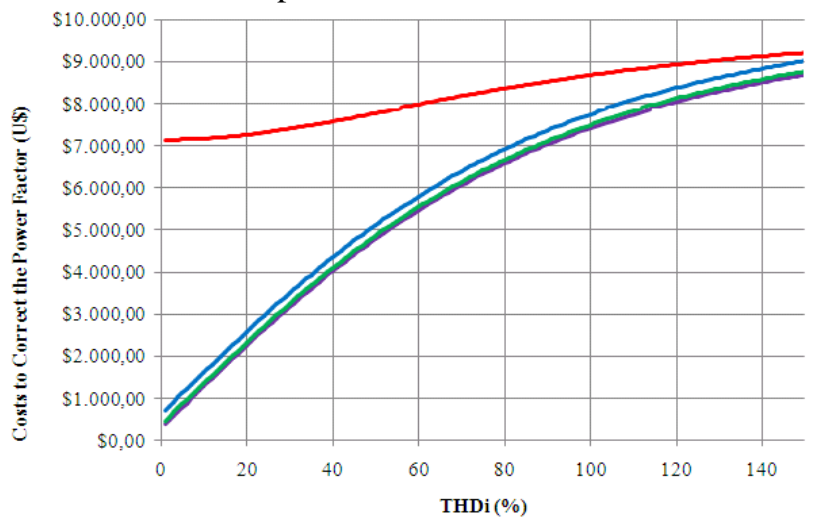$$
\begin{aligned}
& \text { - Conventional Active Filter } \quad \text { Proposed Active Filter (F.P. }=0,92) \\
& \text { - Proposed Active Filter (F.P. }=0,95 \text { ) - Proposed Active Filter (F.P. }=1 \text { ) }
\end{aligned}
$$

Fig. 3. Comparison between the costs to correct the power factor using the conventional and the proposed strategies to drive an APF.

Figure 3 shows that, to a load with $20 \%$ harmonic distortion, the cost to fix the power factor with the use of conventional strategy in an APF is approximately US\$ $7,300.00$. The cost to fix the power factor to 0.95 using the proposed strategy to drive the APF plus the use of capacitors is approximately US\$2,400.00. That is, for the correction of this hypothetical load one can reduce the investment in approximately $66 \%$ if uses the proposed strategy. In a real case this cost could be even lower, since the power factor required in Brazil is 0.92 and the calculation was done to achieve a power factor equal to 0.95 .

It is clear, therefore, that the study proposed in this work is possible, since the proposed strategy of control becomes very advantageous in relation to the conventional one for the currently existing load scenarios in industrial, commercial and residential sector. 


\section{Topology}

Figure 4 shows the topology used to validate the strategy proposed in this work. It is the full-bridge inverter composed by four bi-directional switches in current ( $\mathrm{Sn}$, $\mathrm{Dn})$, an inductor (Lf) and a filter capacitor (Cf). This topology has several features that make it the natural solution for an active filter [6]:

- Possibility of modulation at three levels, reducing the coupling inductance;

- Just one capacitor in the DC bus, which simplifies the voltage control loop;

- Use of four switches that will be subjected to the DC bus voltage and the control circuit is relatively simple.

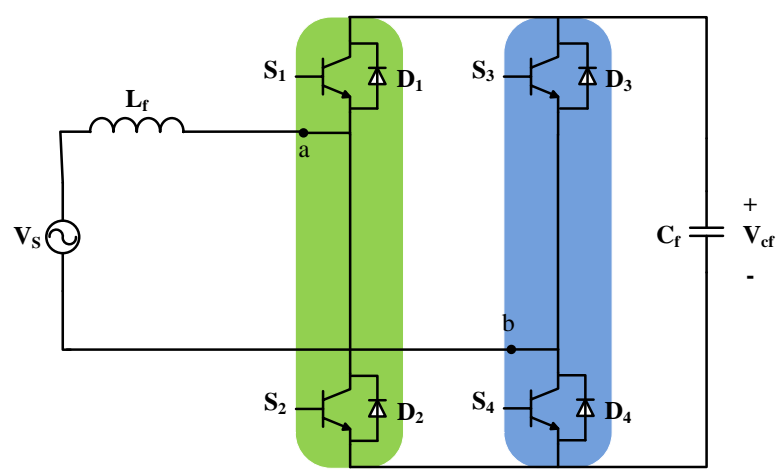

Fig. 4. The full-bridge inverter as an APF.

In Table I are shown the main parallel active filter specifications.

Table I. The active filter specifications

\begin{tabular}{|l|c|}
\hline Specifications & Value \\
\hline Processed Reactive Power & $500 \mathrm{VAr}$ \\
\hline RMS Grid Voltage & $110 \mathrm{~V}$ \\
\hline Grid Frequency & $60 \mathrm{~Hz}$ \\
\hline Current Variation & $15 \%$ \\
\hline $\begin{array}{l}\text { Filter Capacitor (Cf) Voltage } \\
\text { Variation }\end{array}$ & $10 \%$ \\
\hline Commutation Frequency (fs) & $20 \mathrm{kHz}$ \\
\hline DC Bus Voltage & $200 \mathrm{~V}$ \\
\hline
\end{tabular}

It is used the three level SPWM (Sinewave Pulse Width Modulation) because the greater the number of voltage levels, lower coupling inductance and increased the frequency of modulation between points " $a$ " and " $b$ " (Fig. 4). From this information one can determine the value of the coupling inductance which for this project was $2.5 \mathrm{mH}$. For the correct operation of the filter the bus voltage must be at least equal to the peak voltage of the network because it needs to provide energy to the network at any instant of time. Usually the voltage on the DC bus is $30 \%$ higher than the peak voltage of the network. For this project it is used a DC bus voltage of $200 \mathrm{~V}$ and a ripple of $10 \%$.

The active elements are formed by the IRAMY20UP60B IGBT module, which meets all the needs of the active filter.

Table II shows a summary of the main components used in the power stage of the parallel active filter.
Table II. Active Filter Main Devices

\begin{tabular}{|l|c|l|}
\hline \multicolumn{1}{|c|}{ Device } & Value & \multicolumn{1}{c|}{ Description } \\
\hline Coupling Inductor & $2,5 \mathrm{mH}$ & NEE Core 42/21/20 Thorton \\
\hline DC Bus Capacitor & $470 \mu \mathrm{F}$ & 4 Electrolytic Capacitors \\
\hline Switches & & IGBT IRAMY20UP60B \\
\hline
\end{tabular}

\section{Strategy control of the active filter}

The main purpose of the shunt APF system is to supply the harmonics absorbed by the nonlinear load, in order to provide the grid current with low-harmonic content [5]. Also APF are powerful tools for the compensation of reactive power and unbalance of nonlinear and fluctuating loads [1].

The strategy used in this work intends to correct only the distortion factor and none action is intended to the displacement factor. To meet this specification it is required three control loops. The outer voltage loop is responsible for capacitor-voltage regulation while the inner current loop performs the reference current signal tracking [6]. An additional control loop is needed to generate the current reference from the system network. Unlike the usual concepts of conventional APF, where the sine reference is obtained through a sample of the network voltage, the proposed strategy needs a sine reference from the current network system. A suitable control filters only the fundamental component of the current network system, generating with the signal coming from the voltage loop a sine reference for the current loop control. The network is compared with the reference sine current. The error signal passes through a loop with an instantaneous average values control generating then the command signal to the switches. In this way, the APF will compensate only the harmonic distortion and no action will do for the linear reactive.

Figure 5 shows the block diagram of the APF with the three loops used. As shown in Figure 5, the DC bus voltage (Vcf) is monitored and compared with a reference voltage (Vref) and the resulting error signal passes through a voltage meter and this signal is multiplied by a sine reference from the loop of sine reference that monitors the network. This multiplication generates the current reference (Isref). The current (Is) is compared with the reference current (Isref) and the error signal passes through a loop controlled by instantaneous average values generating the command signals to the switches.

\section{Experimental Results}

An experimental shunt active-filter prototype was built using a 500VA full bridge as the power inverter and a Freescale DSC 56F8323 as the digital control platform.

The same parameters listed in Tables I and II are used in the experimental analysis. The grid supplies four types of load: a rectifier with an $\mathrm{RC}$ load, a rectifier with an RL load, a purely resistive load and an RL linear load.

Figure 6 shows the schematic of power and control with the sensors location and the interface circuits responsible for conditioning the input signals. 


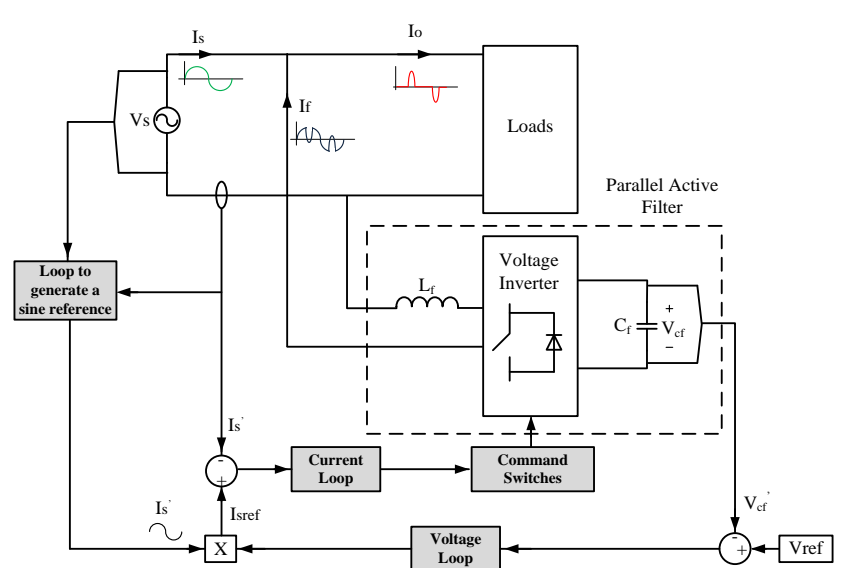

Fig. 5. The parallel active filter control strategy diagram.

From the prototype shown in Figure 7 it was possible to obtain the experimental results from the four distinct loads. Figures 8, 9, 10 and 11 show the experimental results obtained from the prototype. In all these figures the waveforms in red are for the grid voltage and in green are, respectively, the waveforms of load current, filter current and grid current. The grid voltage presents a voltage THD of $3.5 \%$ in all of the experiments.

Figure 8 shows the experimental results obtained from the rectifier with an RC load. One can see through this figure that the APF acted appropriately in current harmonics mitigation by reducing the total harmonic distortion from $71.6 \%$ to $5.2 \%$. The grid current is in advance when compared with the grid voltage. It occurs because the APF do not act in the displacement factor.

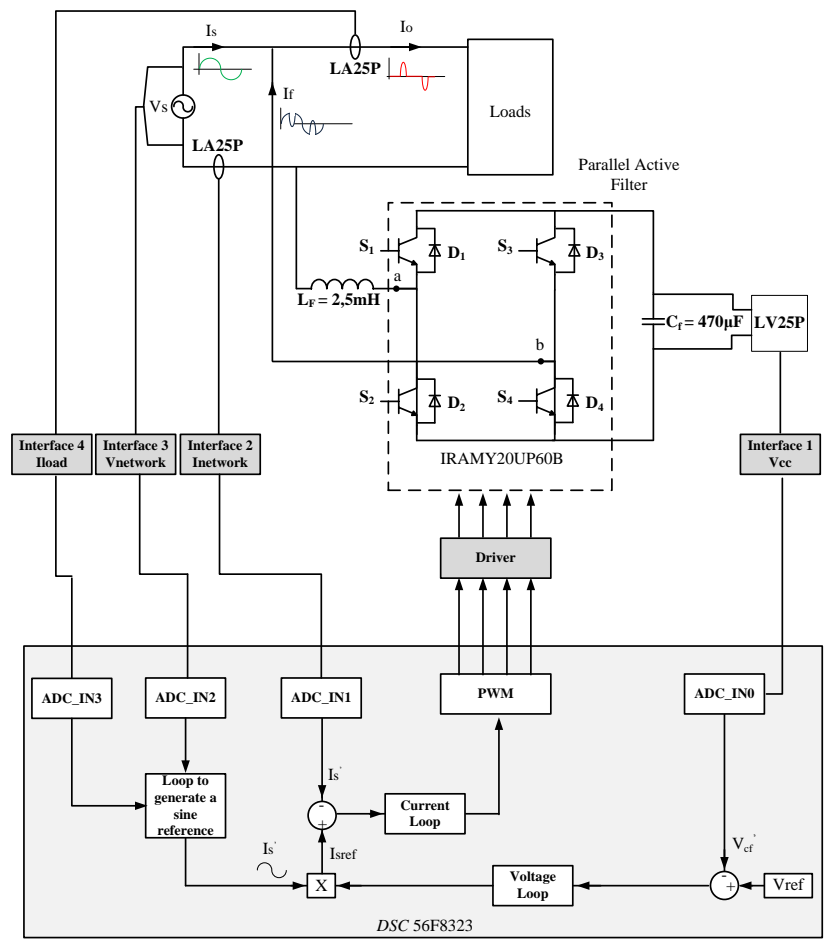

Fig. 6. Measurement schematics.

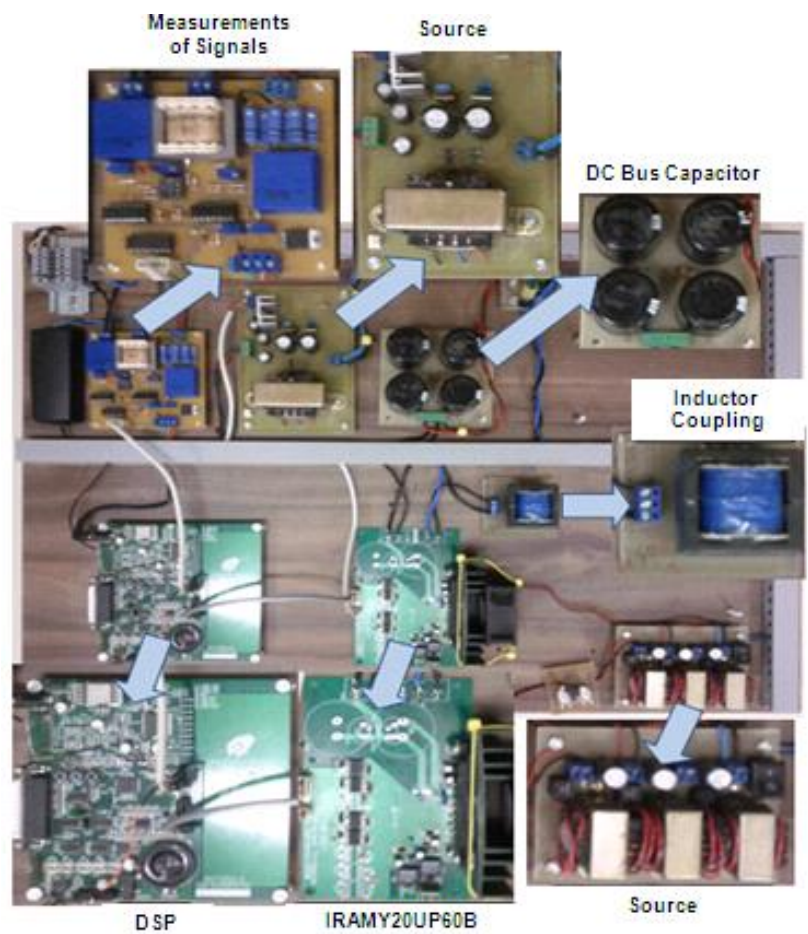

Fig. 7. A photo of the implemented prototype.

Figure 9 shows the experimental results for the singlephase rectifier with an RL load. This figure shows the filter acting appropriately in current harmonics mitigation by reducing the total harmonic distortion from $26.6 \%$ to $4.0 \%$. One can realize that this is a load with inductive characteristic and it has a displacement factor delayed, for this reason, the grid current is lagging the network voltage, proving that the filter only compensates the harmonics.

Figure 10 shows the experimental results to the purely resistive linear load. One can see through this figure that the filter current is practically null. This small current comes from the energy needed to keep the DC bus voltage and keeping the filter losses.

Figure 11 shows the experimental results from the linear RL load. For a linear load with inductive characteristic it is clearly seen that the grid current is behind network voltage, proving that the APF only compensates for the distortion factor, not acting on the displacement factor.

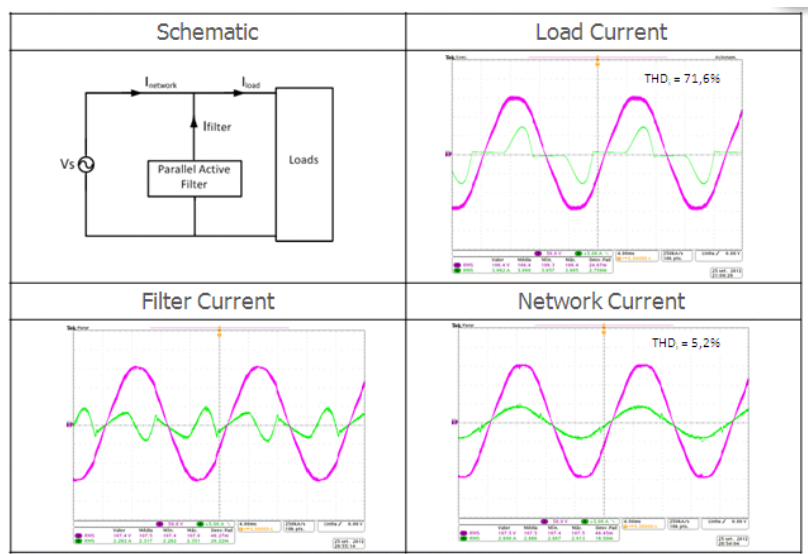

Fig. 8. Results for a single-phase rectifier with an RC load. 


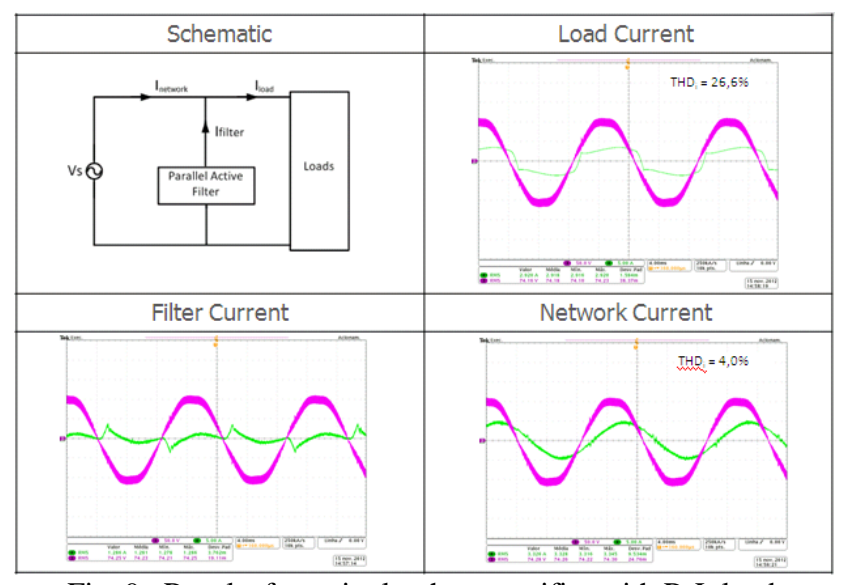

Fig. 9. Results for a single-phase rectifier with R-L load.

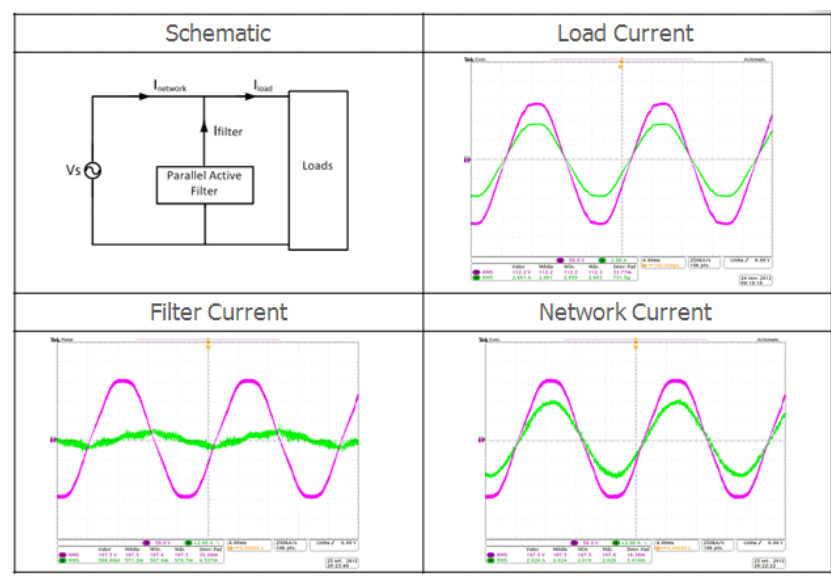

Fig. 10. Results from the purely resistive load.

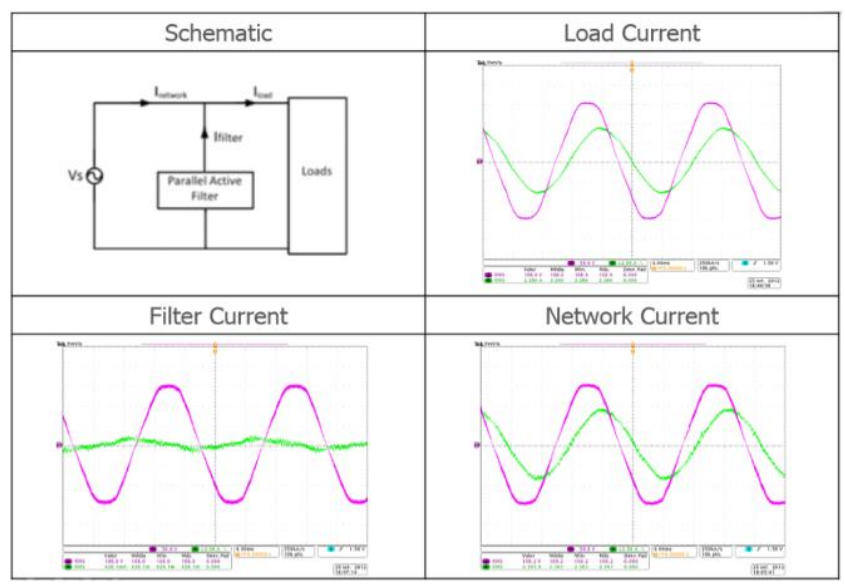

Fig. 11. Results from the linear RL load.

\section{Conclusion}

The main objective of this work was the implementation of an active filter for harmonic distortion factor correction only. The main difference to a conventional active filter is the control strategy proposed. The conventional active filter processes all the reactive energy consumed by the load, i.e. the active filter compensates the distortion factor and the displacement factor to regulate the power factor. On the other hand, the proposed active filter control strategy restricts the compensation only to the harmonic distortion factor without processing the linear reactive power. Through the implementation of an active power filter of 500VA laboratory prototype it was found the effectiveness of the proposed parallel active filter, showing that it compensates only the harmonic distortion without action in the displacement factor. The displacement factor could be compensated by capacitors, since this method is extremely widespread and efficient for this type of compensation. It was made a comparison study of processed power by a conventional active power filter compensating the entirely reactive power and another compensating only the harmonic contents, proving that the processed power by the active filter is lower than the conventional one.

\section{Acknowledgement}

The authors would like to thank the Brazilian National Council for the Improvement of Higher Education (CAPES) for its financial support.

\section{References}

[1] P. Mattavelli, "A closed-loop selective harmonic compensation for active filters", IEEE Transactions on Industry Applications, vol. 37, n. 1, pp.81 - 89, 2001.

[2] C. A. Gougler, J. R. Johnson, "Parallel active harmonics filter: economical viable technology", in proc. of IEEE PES 1999 Winter Meeting, vol. 2, pp. 1142 - 1146, 1999.

[3] X. Xiangning, X. Yonghai, L. Hao, M. Yulong, "Experimental Study and Comparison of Hybrid Active Filter with Parallel Active Filter", in proc. of IEEE PEDS, pp. 566-571, 2003.

[4] V. F. Corasaniti, M. B. Barbieri, P. L. Arnera, M. I. Valla, "Hybrid active filter for reactive and harmonics compensation in a distribution network", IEEE Transactions on Industrial Electronics, vol. 56, n. 3, pp.670 - 677, 2009.

[5] J. Miret, M. Castilla, J. Matas, J. M. Guerrero, J. C. Vasquez, "Selective Harmonic-Compensation Control for Single-Phase Active Power Filter With High Harmonic Rejection", IEEE Transactions on Industrial Electronics, vol. 56, n. 8, pp. 3117-3127, August 2009.

[6] F. Pottker, I. Barbi, D. Lindeke, S. A. Mussa, "Single Phase Active Power Filter Controlled with a Digital Signal Processor - DSP", in proc. of IEEE PESC, pp. 1024-1027, 2004.

[7] M. C. I. Silva, Correção do Fator de Potência de Cargas Industriais com Dinâmica Rápida. Master Dissertation, Federal University of Minas Gerais, Belo Horizonte, Brazil, 2009.

[8] O. Solano, C. Viviescas, M. Mantilla, J. Petit, A. Acevedo, "Experimental evaluation of DC bus voltage control in Shunt Active Power Filter with split capacitor using real time hardware in the loop simulation", in proc. of IEEE EPEC, pp.398-403, 2011. 